\title{
Supply chain networks, wages, and labor productivity: insights from Lagrange. analysis and computations
}

\author{
Anna Nagurney ${ }^{1}$ (D)
}

Received: 21 July 2021 / Accepted: 13 December 2021 / Published online: 5 January 2022

(c) The Author(s), under exclusive licence to Springer Science+Business Media, LLC, part of Springer Nature 2022

\begin{abstract}
The COVID-19 pandemic has dramatically demonstrated the importance of labor to supply chain network activities from production to distribution with shortfalls in labor availability, for numerous reasons, resulting in product shortages and the reduction of profits of firms. Even as progress has been made through vaccinations, issues associated with labor are still arising. Increasing wages is a strategy to enhance labor productivity and, also to ameliorate, in part, labor shortages, but has not, until this work, been explored in a full supply chain network context. Specifically, in this paper, a game theory supply chain network model is constructed of firms competing in producing a substitutable, but differentiated, product, and seeking to determine their equilibrium product path flows, as well as hourly wages to pay their workers, under fixed labor amounts associated with links, and wage-responsive productivity factors. The theoretical and computational approach utilizes the theory of variational inequalities. We first introduce a model without wage bounds on links and then extend it to include wage bounds. Lagrange analysis is conducted for the latter model, which yields interesting insights, as well as an alternative variational inequality formulation. A series of numerical examples reveals that firms can gain in terms of profits by being willing to pay higher wages, resulting in benefits also for their workers, as well as consumers, who enjoy lower demand market prices for the products. However, sensitivity analysis should be conducted to determine the range of such wage bounds. Ultimately, we observed, that the profits may decrease and then stabilize. This work adds to the literature on the integration of concepts from economics and operations research for supply chain networks and also has policy implications.
\end{abstract}

Keywords Labor · Productivity · Wages $\cdot$ Supply chains $\cdot$ Networks · Game theory

\section{Introduction}

The COVID-19 pandemic has dramatically shown the importance of labor to global supply chains. Disruptions associated with lack of labor, due to reasons including illnesses and

Anna Nagurney

nagurney@isenberg.umass.edu

1 Department of Operations and Information Management, Isenberg School of Management, University of Massachusetts, Amherst 01003, Massachusetts, USA 
deaths and the need for quarantining and social distancing, among others, have negatively impacted the production, transportation, storage, and distribution of products from PPEs and other healthcare products to cleaning supplies and even food items from meat to fresh produce (cf. Burki [3], Corkery and Yaffe-Bellany [8], Flannery [16], Nickel and Walljasper ([35]), Schrotenboer [41]). Lack of labor due to COVID issues has resulted in port congestion, since there was not sufficient labor to unload containers ( $\mathrm{db}$ group [13]), produce getting spoiled since it could not be harvested in a timely manner (Nagurney [25], Luckstead, Nayga, Jr., and Snell [23]), the culling of animals due to shortfalls in processing (Polansek and Huffstutter [37]), and products not delivered in time due to unavailability of freight service providers, especially truckers (Cardona [4]). And, now, as more and more individuals are getting vaccinated against COVID-19 and many areas are "opening up," many industries continue to deal with labor shortages and this is affecting the economy as well as the availability of goods and their prices (Conerly [7]).

There has been much media attention recently noting that numerous companies are raising wages to attract workers with such a strategy being taken by firms in the hospitality industry, including restaurants, such as Chipotle and Starbucks, as well as online retailers such as Wayfair and also Walmart, Target, and Costco (Reuter and Winck [38]). Even Amazon has been raising wages in order to attract workers (Palmer [36]).

Interesting, and also highly relevant, is recent evidence from practice that raising wages may enhance labor productivity, including that in manufacturing (Karp [18]). This, in turn, may alleviate some of the labor shortages. Wolters and Zilinsky [46] had reviewed the literature and theory on how wage increases influence productivity. They state that higher wages motivate employees to work harder, which is supported by research done by Yellen [48] and by Levine [21] in the case of large manufacturing companies. Wolters and Zilinsky [46] also note that higher wages are associated with better health and concomitant greater stamina and less illness, which enhance worker productivity. They further emphasize that laborers who are overly preoccupied with income security perform less well at work and cite a [47] development report that references many field studies, and that acknowledges that poverty taxes one's mental capacities and self-control. Fisman and Luca [15], more recently, state that paying workers wages that are above the market rate can also be an important motivating force for a company's employees. Lolla and O'Rourke [22], in their two-year quasi-experiment in an apparel factory, note the positives of increased wages on both productivity of the workers and on profits of the manufacturer.

Van Biesebroeck [45] surveyed the empirical and theoretical literature on wages and productivity and provided an extensive list of references. Strain [43] argues that, based on empirical evidence, the link between productivity and wages is strong.

In this paper, we explore the impacts of wage-responsive productivity of labor in supply chain networks on product consumer prices and profits of competing firms. We utilize a game theory perspective grounded in the theory of variational inequalities (cf. [24]). The only previously published work on the incorporation of labor in supply chain networks using game theory is that of [26]. That work considers three different sets of constraints on labor - bounds on supply chain network links; a bound on labor across a tier of supply chain links corresponding to production, transportation, etc., or a bound on labor availability in the supply chain network economy. In the case of the latter two sets of constraints, the firms compete for labor, while maximizing their profits, which corresponds to a Generalized Nash Equilibrium (cf. Debreu [14] and Arrow and Debreu [1]) as opposed to a Nash Equilibrium (cf. Nash [33,34]) as in the first case. This paper, in contrast to the previous work, differs in considering the following: 
1. Each link productivity factor is an increasing function of the wage on the link (and not fixed). Hence, the productivity factors are wage-responsive;

2. The amount of labor available on each link is fixed (and is not a variable);

3. There is an upper bound on the wage on each link that a firm desires to pay. The previously noted work considered bounds on labor and not on wages;

4. We conduct Lagrange analysis on the model, which yields an alternative variational inequality, amenable for elegant solution, plus managerial insights;

5. We conduct sensitivity analysis on impacts of changes to wage-responsive productivity as well as bounds on wages that firms are willing to pay their employees.

This paper also extends the framework in [27] by considering fixed amounts of labor on each link, wage-dependent productivity factors, and the application of Lagrange analysis, which is done here, for the first time, in a supply chain network game theory context with path flow (and not just link flow) variables.

The Nobel laureate Joseph Stiglitz [42] also considered wage-responsive (dependent) productivity of labor but not in a supply chain network context as we do here, wherein different links of a firm associated with production, transportation, storage, and distribution and different sites can have distinct wage-responsive productivity factors and, of course, these can differ also across the supply chain links of the competing firms.

This paper adds to the recent literature on novel applications and extensions of supply chain networks using the rigorous methodology of the theory of variational inequalities to address challenges in the commercial sector (cf. Nagurney, Yu, and Besik [32], Saberi et al. [39], Nagurney, Besik, and Nagurney (2019), Yu et al. [49]) and inspired by the COVID19 pandemic (see, e.g., Nagurney, Daniele, and Nagurney [30], Daniele and Sciacca [12], Nagurney [25], Nagurney and Dutta [31], Salarpour and Nagurney [40]). However, as noted above, there has been limited research on game theory and supply chain networks with the inclusion of the critical human resource - that of labor.

This paper is organized as follows. Section 2 constructs the supply chain network game theory models with wage-responsive productivity factors and fixed labor on links. We first, for definiteness, present the model without wage bounds and then the model with wage bounds on the links. The governing equilibrium conditions are stated and variational inequality formulations provided. We then, for the model with wage bounds, conduct Lagrange analysis, which yields an alternative variational inequality with nice features for algorithmic computations. The Lagrange analysis also provides managerial insights. In Sect. 3, we outline the computational procedure and identify the closed-form expression structure of the resulting algorithmic steps at each iteration. Conditions for convergence are given. We then report on the results for the application of the algorithm in solving a series of numerical examples. The numerical examples reveal the benefits of firms being willing to pay higher wages to their workers in terms of profits for the firms, higher wages for the workers, and lower demand market prices for consumers. However, it is imperative that a holistic approach be taken and that the full picture of supply chain competition among firms is captured. We also find that, in the case of fixed labor associated with the links, and wage-responsive productivity factors, that, after a particular bound on wages is achieved, that a profit of a firm may decrease, and, ultimately, profits of firms may stabilize. We summarize the results of this paper in Sect. 4, where we, in addition, outline suggestions for future research. 


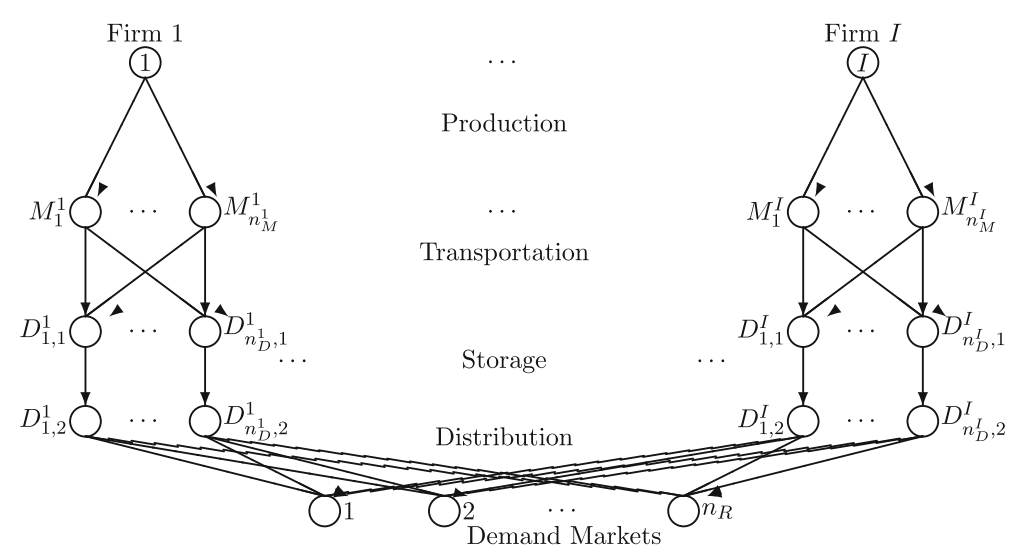

Fig. 1 The Supply Chain Network Topology

\section{The supply chain network game theory models with wage-responsive productivity}

In the supply chain network economy there are $I$ firms, with a typical firm denoted by $i$. Each firm produces a product, which is substitutable but differentiated. The firms compete in an oligopolistic manner, each seeking to maximize its profits and has its own supply chain network, with the supply chain networks of all firms, as depicted in Fig. 1. The supply chain network of a given firm consists of production links, transportation links, and the storage and distribution links. Observe that a firm, according to Fig. 1, can have multiple production sites and multiple storage facilities. The firms sell their products at the same demand markets. The supply chain network topology in Fig. 1 is only representative and can be modified according to the specific application under study. The notation for the model follows closely that in Nagurney [26].

We let $G=[N, L]$ represent the graph consisting of the set of nodes $N$ and the set of links $L$ as in Fig. 1. $P_{k}^{i}$ denotes the set of paths in firm $i$ 's supply chain network with a path $p$ originating in the top tier node $i$ and ending in a demand market $k$, with $i=1, \ldots, I$ and $k=1, \ldots, n_{R} . P^{i}$ is then the set of all paths of firm $i ; i=1, \ldots, I$. We group all the latter paths into the set $P$ with $n_{P}$ elements. Observe from Fig. 1 that the supply chain networks of the firms have no links in common.

Table 1 contains the basic model notation. All vectors are column vectors.

\subsection{The model without wage bounds}

We first present the conservation of flow equations and then the equations relating labor on each link to the product output on the link. Here we assume a linear production function, as in economics, but one that is wage-responsive, as in Table 1.

The model without wage bounds is presented first and then extended to include wage bounds in Sect. 2.2, where the Lagrange analysis is conducted.

All the product paths flows must be nonnegative, that is:

$$
x_{p} \geq 0, \quad \forall p \in P^{i}, \quad \forall i .
$$


Table 1 Notation for the Models with Wage-Dependent Labor Productivity

\begin{tabular}{|c|c|}
\hline Notation & Definition \\
\hline$x_{p} ; p \in P_{k}^{i}$ & $\begin{array}{l}\text { nonnegative product flow on path } p \text { beginning at firm } \\
\text { node } i \text { and ending at demand market } k ; i=1, \ldots, I \text {; } \\
k=1, \ldots, n_{R} \text {. Firm } i \text { 's product path flows are } \\
\text { grouped into the vector } x^{i} \in R_{+}^{n}{ }^{i} \text {. All the firms' } \\
\text { product path flows are grouped into the vector } x \in \\
R_{+}^{n_{P}} \text {. }\end{array}$ \\
\hline$d_{i k}$ & $\begin{array}{l}\text { demand for the product of firm } i \text { at demand market } \\
k ; i=1, \ldots, I ; k=1, \ldots, n_{R} \text {. We group the }\left\{d_{i k}\right\} \\
\text { elements for firm } i \text { into the vector } d^{i} \in R_{+}^{n_{R}} \text {. All the } \\
\text { demands are grouped into the vector } d \in R_{+}^{I \times n_{R}} \text {. }\end{array}$ \\
\hline$f_{a}$ & $\begin{array}{l}\text { nonnegative flow of the product on link } a, \forall a \in L \text {. All } \\
\text { the link flows are grouped into the vector } f \in R_{+}^{n_{L}} \text {. }\end{array}$ \\
\hline$l_{a}^{\text {fixed }}$ & $\begin{array}{l}\text { fixed amount of labor on link } a \text { (typically denoted in } \\
\text { person hours). }\end{array}$ \\
\hline$w_{a}$ & $\begin{array}{l}\text { wage for a unit of labor on link } a \text { per hour the cog- } \\
\text { nizant firm is willing to pay, on links } a \in L^{i} \text { for } \\
i=1, \ldots, I \text {. }\end{array}$ \\
\hline $\bar{w}_{a}$ & $\begin{array}{l}\text { upper bound on wage on link } a \text { that the firm respon- } \\
\text { sible for the link is willing to pay, for } a \in L^{i} \text { for } \\
i=1, \ldots, I \text {. }\end{array}$ \\
\hline$\alpha_{a} w_{a}$ & $\begin{array}{l}\text { productivity factor relating input of labor to out- } \\
\text { put of product flow on link } a \text {, where } \alpha_{a} \text { is given } \\
\forall a \in L \text { and is positive and is refered to as the wage- } \\
\text { responsiveness productivity factor. }\end{array}$ \\
\hline$\hat{c}_{a}(f)$ & total operational cost associated with link $a, \forall a \in L$. \\
\hline$\rho_{i k}(d)$ & $\begin{array}{l}\text { demand price function for firm } i \text { 's product at demand } \\
\text { market } k ; i=1, \ldots, I ; k=1, \ldots, n_{R} \text {. }\end{array}$ \\
\hline
\end{tabular}

Also, the demand for each product must be satisfied at each demand market, that is, for each firm $i: i=1, \ldots, I$ :

$$
\sum_{p \in P_{k}^{i}} x_{p}=d_{i k}, \quad k=1, \ldots, n_{R} .
$$

The link flows of each firm $i ; i=1, \ldots, I$, are related to the product path flows as follows:

$$
f_{a}=\sum_{p \in P} x_{p} \delta_{a p}, \quad \forall a \in L^{i},
$$

where $\delta_{a p}=1$, if link $a$ is contained in path $p$, and 0 , otherwise.

One of the novel features of our model is the use of the following equations:

$$
f_{a}=\alpha_{a} w_{a} l_{a}^{\text {fixed }}, \quad \forall a \in L^{i}, \quad i=1, \ldots, I,
$$

so that the greater the value of the wage $w_{a}$ on link $a$, the more productive the labor on the link.

The utility function of each firm $i, U^{i} ; i=1, \ldots, I$, represents the profit, which is the difference between its revenue, $\sum_{k=1}^{n_{R}} \rho_{i k}(d) d_{i k}$, and its total operational costs and all the 
wages paid for labor, $\sum_{a \in L^{i}} \hat{c}_{a}(f)-\sum_{a \in L^{i}} w_{a} l_{a}^{\text {fixed }}$, as follows:

$$
U^{i}=\sum_{k=1}^{n_{R}} \rho_{i k}(d) d_{i k}-\sum_{a \in L^{i}} \hat{c}_{a}(f)-\sum_{a \in L^{i}} w_{a} l_{a}^{\text {fixed }} .
$$

The utility functions $U_{i} ; i=1, \ldots, I$, are assumed to be concave, with the demand price functions being monotone decreasing and continuously differentiable and with the total operational link cost functions being convex and also continuously differentiable.

Due to (2), we can define demand price functions $\tilde{\rho}_{i k}(x) \equiv \rho_{i k}(d), \forall i, \forall k$, and, due to (3), we can define the total operational link cost functions $\tilde{c}_{a}(x) \equiv \hat{c}_{a}(f), \forall a \in L$. Also, using (4), and, subsequently, (3), we conclude that

$$
w_{a} l_{a}^{\text {fixed }}=\frac{f_{a}}{\alpha_{a} l_{a}^{\text {fixed }}} l_{a}^{\text {fixed }}=\frac{\left(\sum_{p \in P} x_{p} \delta_{a p}\right)}{\alpha_{a}}, \quad \forall a \in L .
$$

We also define $\tilde{U}_{i}(x) \equiv U_{i} ; i=1, \ldots, I$ and, by also making use of (2) again, we obtain:

$$
\tilde{U}^{i}(x)=\sum_{k=1}^{n_{R}} \sum_{p \in P_{k}^{i}} \tilde{\rho}_{i k}(x) x_{p}-\sum_{a \in L^{i}} \tilde{c}_{a}(x)-\sum_{a \in L^{i}} \frac{\left(\sum_{p \in P} x_{p} \delta_{a p}\right)}{\alpha_{a}}, \quad i=1, \ldots, I .
$$

The feasible set $K_{i}$ for firm $i$ is defined as: $K_{i} \equiv\left\{x^{i} \mid x^{i} \in R_{+}^{n_{P^{i}}}\right.$, for $\left.i=1, \ldots, I\right\}$. Also, $K \equiv \prod_{i=1}^{I} K_{i}$.

Each firm $i ; i=1, \ldots, I$, seeks to determine its vector of strategies consisting of its product path flows $x^{i} \in R_{+}^{n_{P i}}$ that maximizes its profits, $\tilde{U}^{i}(x)$, satisfying the Nash [33,34] equilibrium conditions in the definition below.

\section{Definition 1 Supply Chain Network Nash Equilibrium for the Game Theory Model Without Wage Bounds}

A path flow pattern $x^{*} \in K$ is a supply chain network Nash Equilibrium if for each firm $i$; $i=1, \ldots, I$ :

$$
\tilde{U}^{i}\left(x^{i *}, \hat{x}^{i *}\right) \geq \tilde{U}^{i}\left(x^{i}, \hat{x}^{i *}\right), \quad \forall x^{i} \in K_{i},
$$

where $\hat{x}^{i *} \equiv\left(x^{1 *}, \ldots, x^{i-1 *}, x^{i+1 *}, \ldots, x^{I *}\right)$.

According to (8), a Nash equilibrium is achieved when no firm, acting unilaterally, can improve upon its profits.

\section{Variational Inequality Formulations}

Using the classical theory of Nash equilibria and variational inequalities, since, under our imposed assumptions on the underlying functions, the utility functions for each firm are concave and continuously differentiable (cf. Gabay and Moulin [17] and Nagurney [24]), it follows that the solution to the above Nash Equilibrium problem (see Nash $[33,34]$ ) coincides with the solution of the variational inequality problem: determine $x^{*} \in K$, such that

$$
-\sum_{i=1}^{I} \sum_{k=1}^{n_{R}} \sum_{p \in P_{k}^{i}} \frac{\partial \tilde{U}^{i}\left(x^{*}\right)}{\partial x_{p}} \times\left(x_{p}-x_{p}^{*}\right) \geq 0, \quad \forall x \in K,
$$

which, in expanded form, is: determine $x^{*} \in K$, such that 


$$
\begin{aligned}
& \sum_{i=1}^{I} \sum_{k=1}^{n_{R}} \sum_{p \in P_{k}^{i}}\left[\frac{\partial \tilde{C}_{p}\left(x^{*}\right)}{\partial x_{p}}+\sum_{a \in L^{i}} \frac{1}{\alpha_{a}} \delta_{a p}-\tilde{\rho}_{i k}\left(x^{*}\right)-\sum_{l=1}^{n_{R}} \frac{\partial \tilde{\rho}_{i l}\left(x^{*}\right)}{\partial x_{p}} \sum_{q \in P_{l}^{i}} x_{q}^{*}\right] \\
& \quad \times\left[x_{p}-x_{p}^{*}\right] \geq 0, \forall x \in K,
\end{aligned}
$$

where

$$
\begin{aligned}
& \frac{\partial \tilde{C}_{p}(x)}{\partial x_{p}} \equiv \sum_{a \in L^{i}} \sum_{b \in L^{i}} \frac{\partial \hat{c}_{b}(f)}{\partial f_{a}} \delta_{a p}, \quad \forall p \in P^{i}, \forall i, \\
& \text { and } \frac{\partial \tilde{\rho}_{i l}(x)}{\partial x_{p}} \equiv \frac{\partial \rho_{i l}(d)}{\partial d_{i k}}, \forall p \in P_{k}^{i}, \forall i, \forall k .
\end{aligned}
$$

Once the equilibrium is computed - as we discuss in the next section - we can determine the wages on the links using (4).

\subsection{The model with wage bounds plus Lagrange analysis}

We now extend the above model to introduce upper bounds on wages that the firms are willing to pay their workers per hour. We allow for distinct upper limits on different links. Specifically, the model remains as above except for the addition of the following constraints:

$$
w_{a} \leq \bar{w}_{a}, \quad \forall a \in L .
$$

Making use of (3) and (4), (12) can be reexpressed as:

$$
\sum_{p \in P} x_{p} \delta_{a p} \leq \bar{w}_{a} \alpha_{a} l_{a}^{\text {fixed }}, \quad \forall a \in L .
$$

We define the feasible set $K_{1}^{i} \equiv\left\{x^{i} \geq 0\right.$, and (13) holds for all $\left.a \in L^{i}\right\}$, with $K_{1} \equiv$ $\prod_{i=1}^{I} K_{1}^{i}$. With the wage link upper bounds the statement of the Nash equilibrium according to Definition 1 is still relevant but over the feasible set $K_{1}$. The variational inequality (10) also holds but with the new feasible set $K_{1}$. We remark that, since there are bounds on the wages, the link flows are also bounded, as are the path flows; hence, the feasible set $K_{1}$ is compact. Since all the functions in (10) are continuous, under our imposed assumptions, it follows from the classical theory of variational inequalities (see Kinderlehrer and Stampacchia [19]) that a solution exists.

We define $V(x)$ as

$$
\begin{aligned}
& V(x) \equiv \sum_{i=1}^{I} \sum_{k=1}^{n_{R}} \sum_{p \in P_{k}^{i}}\left[\frac{\partial \tilde{C}_{p}\left(x^{*}\right)}{\partial x_{p}}+\sum_{a \in L^{i}} \frac{1}{\alpha_{a}} \delta_{a p}-\tilde{\rho}_{i k}\left(x^{*}\right)-\sum_{l=1}^{n_{R}} \frac{\partial \tilde{\rho}_{i l}\left(x^{*}\right)}{\partial x_{p}} \sum_{q \in P_{l}^{i}} x_{q}^{*}\right] \\
& \quad \times\left[x_{p}-x_{p}^{*}\right]
\end{aligned}
$$

and observe that the variational inequality with wage bounds can be rewritten as the following minimization problem:

$$
\min _{K_{1}} V(x)=V\left(x^{*}\right)=0 .
$$


In order to construct the Lagrange function, we reformulate the constraints as below, with the associated Lagrange multiplier next to the corresponding constraint:

$$
\begin{gathered}
e_{a}=\sum_{p \in P} x_{p} \delta_{a p}-\bar{w}_{a} \alpha_{a} l_{a}^{\text {fixed }} \leq 0, \quad \lambda_{a}, \forall a, \\
g_{p}=-x_{p} \leq 0, \quad \epsilon_{p}, \forall p,
\end{gathered}
$$

and

$$
\Gamma(x)=\left(e_{a}, g_{p}\right)_{a \in L ; p \in P} .
$$

We now construct the Lagrange function

$$
\begin{aligned}
\mathcal{L}(x, \lambda, \epsilon)= & \sum_{i=1}^{I} \sum_{k=1}^{n_{R}} \sum_{p \in P_{k}^{i}}\left[\frac{\partial \tilde{C}_{p}\left(x^{*}\right)}{\partial x_{p}}+\sum_{a \in L^{i}} \frac{1}{\alpha_{a}} \delta_{a p}-\tilde{\rho}_{i k}\left(x^{*}\right)-\sum_{l=1}^{n_{R}} \frac{\partial \tilde{\rho}_{i l}\left(x^{*}\right)}{\partial x_{p}} \sum_{q \in P_{l}^{i}} x_{q}^{*}\right] \\
& \times\left[x_{p}-x_{p}^{*}\right]+\sum_{a \in L} e_{a} \lambda_{a}+\sum_{p \in P} g_{p} \epsilon_{p}, \forall x \in R_{+}^{n_{P}}, \forall \lambda \in R_{+}^{n_{L}}, \forall \epsilon \in R_{+}^{n_{P}},
\end{aligned}
$$

where $\lambda$ is the vector of all $\lambda_{a}$ s and $\epsilon$ is the vector of all $\epsilon_{p} s$.

The feasible set $K_{1}$ is convex and the Slater condition is satisfied. Indeed, we know that $\Gamma(x)$ is convex and $\exists \bar{x} \in R_{+}^{n_{P}}: \Gamma(\bar{x})<0$, since we can always construct a small enough path flow pattern. Hence, if $x^{*}$ is a minimal solution to problem (15), there exist $\lambda^{*} \in R_{+}^{n_{L}}$ and $\epsilon^{*} \in R_{+}^{n_{P}}$ such that the vector $\left(x^{*}, \lambda^{*}, \epsilon^{*}\right)$ is a saddle point of the Lagrange function (18):

$$
\mathcal{L}\left(x^{*}, \epsilon, \lambda\right) \leq \mathcal{L}\left(x^{*}, \epsilon^{*}, \lambda^{*}\right) \leq \mathcal{L}\left(x, \epsilon^{*}, \lambda^{*}\right)
$$

and

$$
\begin{aligned}
& e_{a}^{*} \lambda_{a}^{*}, \quad \forall a, \\
& g_{p}^{*} \epsilon_{p}^{*}=0, \quad \forall p .
\end{aligned}
$$

From the right-hand side of (19) it follows that $x^{*} \in R_{+}^{n_{P}}$ is a minimal point of the function $\mathcal{L}\left(x, \epsilon^{*}, \lambda^{*}\right)$ in the whole space $R^{n_{P}}$ and, therefore, we have that for all $p \in P_{k}^{i}, \forall i, k$ :

$$
\begin{aligned}
& \frac{\partial \mathcal{L}\left(x^{*}, \epsilon^{*}, \lambda^{*}\right)}{\partial x_{p}}=\left[\frac{\partial \tilde{C}_{p}\left(x^{*}\right)}{\partial x_{p}}+\sum_{a \in L^{i}} \frac{1}{\alpha_{a}} \delta_{a p}-\tilde{\rho}_{i k}\left(x^{*}\right)-\sum_{l=1}^{n_{R}} \frac{\partial \tilde{\rho}_{i l}\left(x^{*}\right)}{\partial x_{p}} \sum_{q \in P_{l}^{i}} x_{q}^{*}\right] \\
& +\sum_{a \in L} \lambda_{a}^{*} \delta_{a p}-\epsilon_{p}^{*}=0,
\end{aligned}
$$

together with conditions (20).

We are now ready to state the following Theorem.

Theorem Conditions (20) and (21) correspond to an equivalent variational inequality to the one in (10), but over the feasible set $K_{1}$, given by: determine $\left(x^{*}, \epsilon^{*}, \lambda^{*}\right) \in R_{+}^{2 n_{P}+n_{L}}$ such that 


$$
\begin{aligned}
& \sum_{i=1}^{I} \sum_{k=1}^{n_{R}} \sum_{p \in P_{k}^{i}}\left[\frac{\partial \tilde{C}_{p}\left(x^{*}\right)}{\partial x_{p}}+\sum_{a \in L^{i}} \frac{1}{\alpha_{a}} \delta_{a p}-\tilde{\rho}_{i k}\left(x^{*}\right)-\sum_{l=1}^{n_{R}} \frac{\partial \tilde{\rho}_{i l}\left(x^{*}\right)}{\partial x_{p}} \sum_{q \in P_{l}^{i}} x_{q}^{*}+\sum_{a \in L^{i}} \lambda_{a}^{*} \delta_{a p}-\epsilon_{p}^{*}\right] \\
& \times\left[x_{p}-x_{p}^{*}\right]+\sum_{p \in P} x_{p}^{*} \times\left[\epsilon_{p}-\epsilon_{p}^{*}\right]+\sum_{a \in L}\left[\bar{w}_{a} \alpha_{a} l_{a}^{f i x e d}-\sum_{p \in P} x_{p}^{*} \delta_{a p}\right] \times\left[\lambda_{a}-\lambda_{a}^{*}\right] \geq 0 \\
& \forall(x, \epsilon, \lambda) \in R_{+}^{2 n_{P}+n_{L}}
\end{aligned}
$$

or simplified as: determine $\left(x^{*}, \lambda^{*}\right) \in R_{+}^{n_{P}+n_{L}}$ such that:

$$
\begin{aligned}
& \sum_{i=1}^{I} \sum_{k=1}^{n_{R}} \sum_{p \in P_{k}^{i}}\left[\frac{\partial \tilde{C}_{p}\left(x^{*}\right)}{\partial x_{p}}+\sum_{a \in L^{i}} \frac{1}{\alpha_{a}} \delta_{a p}+\sum_{a \in L^{i}} \lambda_{a}^{*} \delta_{a p}-\tilde{\rho}_{i k}\left(x^{*}\right)-\sum_{l=1}^{n_{R}} \frac{\partial \tilde{\rho}_{i l}\left(x^{*}\right)}{\partial x_{p}} \sum_{q \in P_{l}^{i}} x_{q}^{*}\right] \\
& \quad \times\left[x_{p}-x_{p}^{*}\right]+\sum_{a \in L}\left[\bar{w}_{a} \alpha_{a} l_{a}^{\text {fixed }}-\sum_{p \in P} x_{p}^{*} \delta_{a p}\right] \times\left[\lambda_{a}-\lambda_{a}^{*}\right] \geq 0, \quad \forall(x, \lambda) \in R_{+}^{n_{P}+n_{L}} .
\end{aligned}
$$

Proof We note, first, that a vector $\left(x^{*}, \epsilon^{*}, \lambda^{*}\right) \in R_{+}^{2 n_{P}+n_{L}}$ satisfying (20) and (21) clearly also satisfies variational inequality (22). We now prove that such a vector also satisfies variational inequality (10).

If we multiply (21) by $\left(x_{p}-x_{p}^{*}\right)$ and sum up with respect to all paths $p \in P$, we get:

$$
\begin{aligned}
& \sum_{i=1}^{I} \sum_{k=1}^{n_{R}} \sum_{p \in P_{k}^{i}}\left[\frac{\partial \tilde{C}_{p}\left(x^{*}\right)}{\partial x_{p}}+\sum_{a \in L^{i}} \frac{1}{\alpha_{a}} \delta_{a p}-\tilde{\rho}_{i k}\left(x^{*}\right)-\sum_{l=1}^{n_{R}} \frac{\partial \tilde{\rho}_{i l}\left(x^{*}\right)}{\partial x_{p}} \sum_{q \in P_{l}^{i}} x_{q}^{*}\right] \times\left[x_{p}-x_{p}^{*}\right] \\
& \quad=\sum_{p \in P}\left[-\sum_{a \in L} \lambda_{a}^{*} \delta_{a p}+\epsilon_{p}^{*}\right] \times\left[x_{p}-x_{p}^{*}\right] .
\end{aligned}
$$

Expanding the right-hand side of (24), we obtain:

$$
\begin{aligned}
& =-\sum_{p \in P} \sum_{a \in L} \lambda_{a}^{*} \delta_{a p} x_{p}+\sum_{p \in P} \sum_{a \in L} \lambda_{a}^{*} \delta_{a p} x_{p}^{*}+\sum_{p \in P} \epsilon_{p}^{*} x_{p}-\sum_{p \in P} \epsilon_{p}^{*} x_{p}^{*}, \\
& =\sum_{a \in L}\left[\bar{w}_{a} \alpha_{a} l_{a}^{\text {fixed }}-\sum_{p \in P} x_{p} \delta_{a p}\right] \lambda_{a}^{*}+\sum_{p \in P} \epsilon_{p}^{*} x_{p}-\sum_{p \in P} \epsilon_{p}^{*} x_{p}^{*},
\end{aligned}
$$

by applying (20) and (13).

The third term in (25b) is clearly nonnegative whereas the fourth term in (25b), due to (20), is equal to zero. The term in brackets in (25b) is nonnegative due to the feasible set $K_{1}$. The conclusion that variational inequality (22) is equivalent to variational inequality (10) with the feasible set $K_{1}$ follows.

Variational inequality (23) then follows from (22) since the nonnegativity of the product path flows $x$ is guaranteed by the feasible set in (23).

We now proceed to conduct the Lagrange analysis. We note that Lagrange analysis has been conducted for other network-based equilibrium problem by Daniele [9-11], Barbagallo, Daniele, and Maugeri [2], Toyasaki et al. [44], Colojanni et al. (2018), Caruso and Daniele [5], and by Nagurney and Daniele [29]. We utilize (21) and consider the case where a path $p$ 
has a positive product flow at the solution, so that $x_{p}^{*}>0$, in which case, due to (20), $\epsilon_{p}^{*}=0$. Assume that for this path none of the link flows are at their upper bounds, in which case, also according to (20), all the $\lambda_{a}^{*}$ s on links on the path are equal to zero. Then (21) yields for such a path $p \in P_{k}^{i}, \forall i, k$ :

$$
\frac{\partial \mathcal{L}\left(x^{*}, \epsilon^{*}, \lambda^{*}\right)}{\partial x_{p}}=\left[\frac{\partial \tilde{C}_{p}\left(x^{*}\right)}{\partial x_{p}}+\sum_{a \in L^{i}} \frac{1}{\alpha_{a}} \delta_{a p}-\tilde{\rho}_{i k}\left(x^{*}\right)-\sum_{l=1}^{n_{R}} \frac{\partial \tilde{\rho}_{i l}\left(x^{*}\right)}{\partial x_{p}} \sum_{q \in P_{l}^{i}} x_{q}^{*}\right]=0
$$

or

$$
\frac{\partial \tilde{C}_{p}\left(x^{*}\right)}{\partial x_{p}}+\sum_{a \in L^{i}} \frac{1}{\alpha_{a}} \delta_{a p}=\tilde{\rho}_{i k}\left(x^{*}\right)-\sum_{l=1}^{n_{R}} \frac{\partial \tilde{\rho}_{i l}\left(x^{*}\right)}{\partial x_{p}} \sum_{q \in P_{l}^{i}} x_{q}^{*} .
$$

(27) has the interpretation that the marginal total operational costs on the path with the inclusion of the sum of the inverses of the wage-responsive productivity factor on links comprising the path are equal to the marginal revenue associated with the product flow on the path. This is a good situation and can be interpreted as the marginal revenue being equal to the full marginal costs, which means that the profit is maximized. Furthermore, from (27), we see that the greater the wage-responsiveness productivity factors on links, making up such a path, the "closer" the marginal revenue on the path to the marginal total operational costs on the path.

On the other hand, assume now that the flow on the path is still positive, but that one or more of the link flows on links making up the path are at their respective upper bounds, in which case, one or more of the $\lambda_{a}^{*} \mathrm{~s}$ will be greater than zero on such links according to (20). Then, (21) implies that:

$$
\frac{\partial \tilde{C}_{p}\left(x^{*}\right)}{\partial x_{p}}+\sum_{a \in L^{i}} \frac{1}{\alpha_{a}} \delta_{a p}+\sum_{a \in L^{i}} \lambda_{a}^{*} \delta_{a p}=\tilde{\rho}_{i k}\left(x^{*}\right)+\sum_{l=1}^{n_{R}} \frac{\partial \tilde{\rho}_{i l}\left(x^{*}\right)}{\partial x_{p}} \sum_{q \in P_{l}^{i}} x_{q}^{*} .
$$

We see from equation (28), that, with one or more link flows at their upper bounds, the marginal revenue associated with the path exceeds the marginal total operational costs on the path with the inclusion of the sum of the inverses of the wage-responsive productivity factor on links comprising the path by an amount $\sum_{a \in L^{i}} \lambda_{a}^{*} \delta_{a p}$, which is not a good situation, since profits could be higher if the bounds were loosened. Also, clearly, the greater the $\alpha_{a}$ s on links $a$ comprising a path, then in both (26) and (28), the marginal revenue on the path is closer to the marginal total operational costs on the path. This reflects that a path is comprised of links on which workers produce more for a given wage (are more productive). The Lagrange multipliers, the $\lambda_{a}^{*}$ s, provide valuable information and may also be interpreted as shadow prices. For example, if one looks back at constraints (13), with which these Lagrange multipliers are associated, one sees that a unit increase in the right-hand side of (13) for link $a$ will result in a $\lambda_{a}^{*}$ increase in profits for the firm. This can be achieved by the cognizant firm (cf. (13)) by raising the wage bound $\bar{w}_{a}$ and/or increasing labor $l_{a}^{\text {fixed }}$ and/or even incentivizing workers to be more sensitive to wages through raising $\alpha_{a}$. Moreover, by comparing the positive $\lambda_{a}^{*} \mathrm{~s}$, a firm can see on which link(s) it makes the most sense to invest in terms of loosening the bounds, with those links with the highest values of their $\lambda_{a}^{*} \mathrm{~s}$, ultimately, being the most important to invest in, from a profit-enhancing perspective. 


\section{The algorithm and numerical examples}

Before presenting the algorithm, we put variational inequality (23) in standard form (cf. Nagurney [24]): determine $X^{*} \in \mathcal{K}$ such that

$$
\left\langle F\left(X^{*}\right), X-X^{*}\right\rangle \geq 0, \quad \forall X \in \mathcal{K},
$$

where $F$ is a given continuous function from $\mathcal{K}$ to $R^{\mathcal{N}}, \mathcal{K}$ is a given closed convex set, and $\langle\cdot, \cdot\rangle$ denotes the inner product in $\mathcal{N}$-dimensional Euclidean space.

We set $\mathcal{K} \equiv R_{+}^{n_{P}+n_{L}}, X \equiv(x, \lambda)$, and $\mathcal{N}=n_{P}+n_{L}$. Also, we define the vector $F \equiv\left(F_{1}, F_{2}\right)$, where the components of $F_{1}$ consist of the elements: $\frac{\partial \tilde{C}_{p}(x)}{\partial x_{p}}+\sum_{a \in L^{i}} \frac{1}{\alpha_{a}} \delta_{a p}+$ $\sum_{a \in L^{i}} \lambda_{a} \delta_{a p}-\tilde{\rho}_{i k}(x)-\sum_{l=1}^{n_{R}} \frac{\partial \tilde{\rho}_{i l}(x)}{\partial x_{p}} \sum_{q \in P_{l}^{i}} x_{q}, \forall p \in P$ and the components of $F_{2}$ consist of the elements: $\bar{w}_{a} l_{a}^{\text {fixed }}-\sum_{p \in P} x_{p} \delta_{a p}, \forall a \in L$. Then, clearly, variational inequality (23) coincides with variational inequality (29), with the above definitions.

We will apply the modified projection method of Korpelevich [20] for the computation of solutions to our numerical examples. We first outline the algorithm and then present the explicit formulae that it takes for our model(s).

The modified projection method is guaranteed to converge if the function $F(X)$ that enters the variational inequality problem (29) is monotone and Lipschitz continuous, provided that a solution exists.

For completeness and easy references we now recall the definitions of monotonicity and Lipschitz continuity of $F(X)$. The function $F(X)$ is said to be monotone, if

$$
\left\langle F\left(X^{1}\right)-F\left(X^{2}\right), X^{1}-X^{2}\right\rangle \geq 0, \quad \forall X^{1}, X^{2} \in \mathcal{K},
$$

and it is Lipschitz continuous, if there exists a constant $\omega>0$, known as the Lipschitz constant, such that

$$
\left\|F\left(X^{1}\right)-F\left(X^{2}\right)\right\| \leq \omega\left\|X^{1}-X^{2}\right\|, \quad \forall X^{1}, X^{2} \in \mathcal{K} .
$$

\subsection{The modified projection method}

The steps of the modified projection method are given below, with $\tau$ denoting an iteration counter:

\section{The Modified Projection Method}

\section{Step 0: Initialization}

Initialize with $X^{0} \in \mathcal{K}$. Set the iteration counter $\tau:=1$ and let $\beta$ be a scalar such that $0<\beta \leq \frac{1}{\omega}$, where $\omega$ is the Lipschitz constant.

\section{Step 1: Computation}

Compute $\bar{X}^{\tau}$ by solving the variational inequality subproblem:

$$
\left\langle\bar{X}^{\tau}+\beta F\left(X^{\tau-1}\right)-X^{\tau-1}, X-\bar{X}^{\tau}\right\rangle \geq 0, \quad \forall X \in \mathcal{K} .
$$

\section{Step 2: Adaptation}

Compute $X^{\tau}$ by solving the variational inequality subproblem:

$$
\left\langle X^{\tau}+\beta F\left(\bar{X}^{\tau}\right)-X^{\tau-1}, X-X^{\tau}\right\rangle \geq 0, \quad \forall X \in \mathcal{K} .
$$

\section{Step 3: Convergence Verification}

If $\left|X^{\tau}-X^{\tau-1}\right| \leq \epsilon$, with $\epsilon>0$, a pre-specified tolerance, then stop; otherwise, set $\tau:=\tau+1$ and go to Step 1 . 
The elegance of this procedure for the computation of solutions to both the supply chain network game theory models with wage-dependent labor can be seen in the following explicit formulae.

\section{Explicit Formulae at Iteration $\tau$ for the Product Path Flows in Step 1}

In particular, we have the following closed form expressions for the path flows in Step 1 for the solution of variational inequality (23):

$$
\begin{aligned}
& \bar{x}_{p}^{\tau}=\max \left\{0, x_{p}^{\tau-1}+\beta\left(\tilde{\rho}_{i k}\left(x^{\tau-1}\right)+\sum_{l=1}^{n_{R}} \frac{\partial \tilde{\rho}_{i l}\left(x^{\tau-1}\right)}{\partial x_{p}} \sum_{q \in P_{l}^{i}} x_{q}^{\tau-1}-\frac{\partial \tilde{C}_{p}\left(x^{\tau-1}\right)}{\partial x_{p}}\right.\right. \\
& \left.\left.-\sum_{a \in L^{i}} \lambda_{a}^{\tau-1} \delta_{a p}-\sum_{a \in L^{i}} \frac{1}{\alpha_{a}} \delta_{a p}\right)\right\}, \\
& \forall p \in P_{k}^{i} ; i=1, \ldots, I ; k=1, \ldots, n_{R} .
\end{aligned}
$$

\section{Explicit Formulae at Iteration $\tau$ for the Lagrange Multipliers in Step 1}

Similarly, we have the following closed form expressions for the Lagrange multipliers in Step 1 at an iteration $\tau$ :

$$
\lambda_{a}^{\tau}=\max \left\{0, \lambda_{a}^{\tau-1}+\beta\left(\sum_{p \in P} x_{p}^{\tau-1} \delta_{a p}-\bar{w}_{a} \alpha_{a} l_{a}^{\text {fixed }}\right)\right\}, \quad \forall a \in L .
$$

The analogues of expressions (34) and (35) for Step 2 follow easily.

As for the solution of variational inequality (10), governing the model without wage upper bounds, (35) is no longer needed, whereas (34) still holds for Step 1 of the modified projection method but with the term: $-\sum_{a \in L} \lambda_{a}^{\tau-1} \delta_{a p}$ removed.

\subsection{Numerical examples}

The modified projection method was coded in FORTRAN and a Linux system at the University of Massachusetts Amherst was used for the numerical computations. The algorithm was initialized with a demand of 40 for each firm-demand market pair, with the demand then equally divided among the associated path flows. The Lagrange multipliers were all initialized to zero. The convergence tolerance was $10^{-7}$ in that the absolute difference between two successive variable iterates differed by no more than this amount. The $\beta$ parameter was set to .01 for all the examples.

There are two firms and two demand markets in the numerical examples. Each firm, has at its disposal, two manufacturing/production plants, a single distribution center, and sells its product at two demand markets, as depicted in Fig. 2.

The total operational link cost functions are:

$$
\begin{aligned}
& \hat{c}_{a}(f)=2 f_{a}^{2}, \quad \hat{c}_{b}(f)=2 f_{b}^{2}, \quad \hat{c}_{c}(f)=.5 f_{c}^{2}, \quad \hat{c}_{d}=.5 f_{d}^{2}, \\
& \hat{c}_{e}(f)=f_{e}^{2}+2 f_{e}, \quad \hat{c}_{f}(f)=.5 f_{f}^{2}, \quad \hat{c}_{g}(f)=.5 f_{g}^{2}, \\
& \hat{c}_{h}(f)=1.5 f_{h}^{2}, \quad \hat{c}_{i}(f)=1.5 f_{i}^{2}+f_{i}, \quad \hat{c}_{j}(f)=f_{j}^{2}+2 f_{j}, \quad \hat{c}_{k}=f_{k}^{2}, \\
& \hat{c}_{l}(f)=.5 f_{l}^{2}, \quad \hat{c}_{m}(f)=.5 f_{m}^{2}+f_{m}, \quad \hat{c}_{n}(f)=f_{n}^{2}+2 f_{n} .
\end{aligned}
$$

The demand price functions are:

$$
\rho_{11}(d)=-5 d_{11}-2 d_{21}+800, \quad \rho_{12}(d)=-5 d_{12}-d_{22}+850,
$$


Firm 1

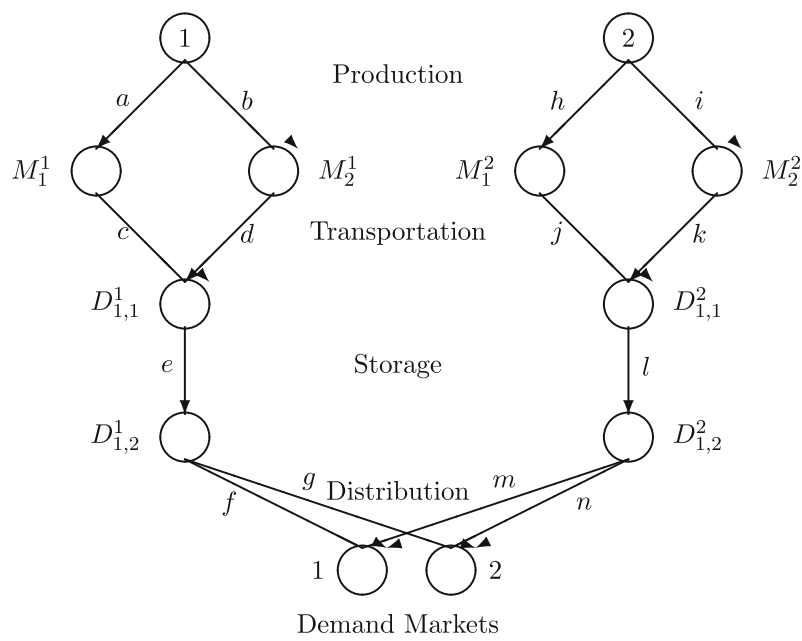

Fig. 2 The Supply Chain Network Topology for the Numerical Examples

$$
\rho_{21}(d)=-3 d_{21}-d_{11}+700, \quad \rho_{22}(d)=-5 d_{22}-.5 d_{12}+750 .
$$

The operational cost functions and demand price functions are constructed to reflect a fairly high value product that is not that expensive to produce, transport, store, and distribute.

The $\alpha_{a}$ and the $l_{a}^{\text {fixed }}$ parameters (cf. (4)) are, for $a \in L$ as follows:

$$
\begin{aligned}
\alpha_{a} & =.5, \alpha_{b}=.5, \alpha_{c}=.3, \alpha_{d}=.3, \alpha_{e}=.4, \alpha_{f}=.5, \alpha_{g}=.3, \\
\alpha_{h} & =.3, \alpha_{i}=.4, \alpha_{j}=.3, \alpha_{k}=.3, \alpha_{l}=.5, \alpha_{m}=.3, \alpha_{n}=.3, \\
l_{a}^{\text {fixed }} & =10, l_{b}^{\text {fixed }}=10, l_{c}^{\text {fixed }}=9, l_{d}^{\text {fixed }}=7, l_{e}^{\text {fixed }}=8, l_{f}^{\text {fixed }}=6, l_{g}^{\text {fixed }}=8, \\
l_{h}^{\text {fixed }} & =3, l_{i}^{\text {fixed }}=3, l_{j}^{\text {fixed }}=9, l_{k}^{\text {fixed }}=9, l_{l}^{\text {fixed }}=8, l_{m}^{\text {fixed }}=7, l_{n}^{\text {fixed }}=8 .
\end{aligned}
$$

The paths are defined as: path $p_{1}=(a, c, e, f)$, path $p_{2}=(b, d, e, f)$, path $p_{3}=$ $(a, c, e, g)$, path $p_{4}=(b, d, e, g)$, path $p_{5}=(h, j, l, m)$, path $p_{6}=(i, k, l, m)$, path $p_{7}=(h, j, l, n)$, and path $p_{8}=(i, k, l, n$,$) .$

\section{Series 1: Examples 1 Through 4}

In this series of examples, we investigate the impacts on product flows, consumer prices, and firm profits of raising the link wage bounds. Example 1 has all link wage bounds $\bar{w}_{a}=10$; Example 2 has all wage bounds $\bar{w}_{a}=15$; Example 3 has all wage bounds $\bar{w}_{a}=20$; and Example 4 has all wage bounds $\bar{w}_{a}=25$.

The remaining data for Examples 1 through 4 are as described above.

\section{Example 1 Results}

The modified projection method converges to the following equilibrium path flow pattern:

$$
\begin{array}{llll}
x_{p_{1}}^{*}=7.19, & x_{p_{2}}^{*}=7.19, & x_{p_{3}}^{*}=8.81, & x_{p_{4}}^{*}=8.81, \\
x_{p_{5}}^{*}=0.59, & x_{p_{6}}^{*}=2.09, & x_{p_{7}}^{*}=8.41, & x_{p_{8}}^{*}=9.91 .
\end{array}
$$

The demand market prices are:

$$
\rho_{11}=722.75, \quad \rho_{12}=743.56, \quad \rho_{21}=677.59, \quad \rho_{22}=722.86 .
$$


The profit for Firm 1 is: 20,530.75 and the profit for Firm 2 is: 13,628.85.

\section{Example 2 Results}

The modified projection method converges to the following equilibrium path flow pattern:

$$
\begin{aligned}
& x_{p_{1}}^{*}=11.19, \quad x_{p_{2}}^{*}=11.19, \quad x_{p_{3}}^{*}=12.81, \quad x_{p_{4}}^{*}=12.81, \\
& x_{p_{5}}^{*}=1.94, \quad x_{p_{6}}^{*}=4.19, \quad x_{p_{7}}^{*}=11.56, \quad x_{p_{8}}^{*}=13.81 .
\end{aligned}
$$

The demand market prices are now:

$$
\rho_{11}=675.81, \quad \rho_{12}=696.54, \quad \rho_{21}=659.22, \quad \rho_{22}=711.82 .
$$

The profit for Firm 1 is now: 26,605.95, whereas the profit for Firm 2 is: 19,213.26.

We see that, with the wage bounds raised, reflecting that the firms are willing to pay their workers more for their labor, the profit for each firm increases, while the demand market prices that consumers pay decrease, signaling a win-win situation.

\section{Example 3 Results}

The modified projection method for Example 3, with all wage bounds set to 20, converges to the following equilibrium path flow pattern:

$$
\begin{aligned}
& x_{p_{1}}^{*}=15.20, \quad x_{p_{2}}^{*}=15.20, \quad x_{p_{3}}^{*}=16.81, \quad x_{p_{4}}^{*}=16.81, \\
& x_{p_{5}}^{*}=3.29, \quad x_{p_{6}}^{*}=6.29, \quad x_{p_{7}}^{*}=14.71, \quad x_{p_{8}}^{*}=17.71 .
\end{aligned}
$$

The demand market prices are now:

$$
\rho_{11}=628.88, \quad \rho_{12}=649.53, \quad \rho_{21}=640.86, \quad \rho_{22}=700.78 .
$$

The profit for Firm 1 is now: 29,897.83 and the profit for Firm 2 is: 24,012.63.

We see that, with the wage bounds further increased that the profits of both firms increase (as compared to their respective values in Examples 1 and 2) and, again, the demand market prices decrease at all demand markets under more generous upper bounds on wages.

\section{Example 4 Results}

The algorithm for Example 4, with all wage bounds now set to 25, converges to the following equilibrium path flow pattern:

$$
\begin{aligned}
& x_{p_{1}}^{*}=18.69, \quad x_{p_{2}}^{*}=18.69, \quad x_{p_{3}}^{*}=20.30, \quad x_{p_{4}}^{*}=20.30, \\
& x_{p_{5}}^{*}=4.67, \quad x_{p_{6}}^{*}=8.42, \quad x_{p_{7}}^{*}=17.83, \quad x_{p_{8}}^{*}=21.58 .
\end{aligned}
$$

The demand market prices are:

$$
\rho_{11}=586.95, \quad \rho_{12}=607.61, \quad \rho_{21}=623.37, \quad \rho_{22}=690.28 .
$$

The profit for Firm 1 is now: 30,425.58 and the profit for Firm 2 is: 28,060.79.

We see that the results are quite robust and reveal that raising wages can benefit both firms as well as consumers.

The computed equilibrium link flows, Lagrange multipliers, and wages (cf. (4)) for Examples 1 through 4 are reported in Table 2 .

From Table 2, we see that, as the wage upper bounds are raised, as we proceed from Example 1 through 4, the wages for labor on all the supply chain network links increase, and this, as discussed above, benefits consumers in terms of lower prices, as well as firms, in terms of higher prices. Furthermore, since in the model, the labor is fixed on all the links, the workers also benefit.

Also, we see that, in Examples 1 through 4, the Lagrange multipliers associated with links $h$ and $i$ are all positive and that the wages on these links are at the upper bounds. The 
Table 2 Equilibrium Link Flows, Lagrange Multipliers, and Hourly Wages for Examples 1 Through 4

\begin{tabular}{|c|c|c|c|c|}
\hline \multirow[t]{2}{*}{ Notation } & \multicolumn{4}{|c|}{ Equilibrium value } \\
\hline & Example 1 & Example 2 & Example 3 & Example 4 \\
\hline$f_{a}^{*}$ & 16.00 & 24.00 & 32.00 & 38.99 \\
\hline$f_{b}^{*}$ & 16.00 & 24.00 & 32.00 & 38.99 \\
\hline$f_{c}^{*}$ & 16.00 & 24.00 & 32.00 & 38.99 \\
\hline$f_{d}^{*}$ & 16.00 & 24.00 & 32.00 & 38.99 \\
\hline$f_{e}^{*}$ & 32.00 & 48.00 & 64.00 & 77.97 \\
\hline$f_{f}^{*}$ & 14.38 & 22.38 & 30.39 & 37.38 \\
\hline$f_{g}^{*}$ & 17.62 & 25.62 & 33.61 & 40.60 \\
\hline$f_{h}^{*}$ & 9.00 & 13.50 & 18.00 & 22.50 \\
\hline$f_{i}^{*}$ & 12.00 & 18.00 & 24.00 & 30.00 \\
\hline$f_{j}^{*}$ & 9.00 & 13.50 & 18.00 & 22.50 \\
\hline$f_{k}^{*}$ & 12.00 & 18.00 & 24.00 & 30.00 \\
\hline$f_{l}^{*}$ & 21.01 & 31.50 & 42.00 & 52.50 \\
\hline$f_{m}^{*}$ & 2.68 & 6.13 & 9.58 & 13.08 \\
\hline$f_{n}^{*}$ & 18.33 & 25.37 & 32.42 & 39.42 \\
\hline$\lambda_{a}^{*}$ & 0.00 & 0.00 & 0.00 & 0.00 \\
\hline$\lambda_{b}^{*}$ & 0.00 & 0.00 & 0.00 & 0.00 \\
\hline$\lambda_{c}^{*}$ & 0.00 & 0.00 & 0.00 & 0.00 \\
\hline$\lambda_{d}^{*}$ & 0.00 & 0.00 & 0.00 & 0.00 \\
\hline$\lambda_{e}^{*}$ & 480.64 & 313.67 & 146.70 & 0.00 \\
\hline$\lambda_{f}^{*}$ & 0.00 & 0.00 & 0.00 & 0.00 \\
\hline$\lambda_{g}^{*}$ & 0.00 & 0.00 & 0.00 & 0.00 \\
\hline$\lambda_{h}^{*}$ & 585.85 & 520.68 & 455.51 & 391.02 \\
\hline$\lambda_{i}^{*}$ & 572.69 & 500.02 & 427.34 & 355.35 \\
\hline$\lambda_{j}^{*}$ & 0.00 & 0.00 & 0.00 & 0.00 \\
\hline$\lambda_{k}^{*}$ & 0.00 & 0.00 & 0.00 & 0.00 \\
\hline$\lambda_{l}^{*}$ & 0.00 & 0.00 & 0.00 & 0.00 \\
\hline$\lambda_{m}^{*}$ & 0.00 & 0.00 & 0.00 & 0.00 \\
\hline$\lambda_{n}^{*}$ & 0.00 & 0.00 & 0.00 & 0.00 \\
\hline$w_{a}^{*}$ & 3.20 & 4.80 & 6.40 & 7.80 \\
\hline$w_{b}^{*}$ & 3.20 & 4.80 & 6.40 & 7.80 \\
\hline$w_{c}^{*}$ & 5.93 & 8.89 & 11.85 & 14.44 \\
\hline$w_{d}^{*}$ & 7.62 & 11.43 & 15.24 & 18.56 \\
\hline$w_{e}^{*}$ & 10.00 & 15.00 & 20.00 & 24.37 \\
\hline$w_{f}^{*}$ & 4.79 & 7.46 & 10.13 & 12.46 \\
\hline$w_{g}^{*}$ & 7.34 & 10.67 & 14.00 & 16.91 \\
\hline$w_{h}^{*}$ & 10.00 & 15.00 & 20.00 & 25.00 \\
\hline$w_{i}^{*}$ & 10.00 & 15.00 & 20.00 & 25.00 \\
\hline$w_{j}^{*}$ & 3.33 & 5.00 & 6.67 & 8.33 \\
\hline$w_{k}^{*}$ & 4.45 & 6.67 & 8.89 & 11.11 \\
\hline
\end{tabular}


Table 2 continued

\begin{tabular}{lllll}
\hline Notation & \multicolumn{4}{l}{ Equilibrium value } \\
\cline { 2 - 5 } & Example 1 & Example 2 & Example 3 & Example 4 \\
\hline$w_{l}^{*}$ & 4.67 & 7.00 & 9.33 & 11.67 \\
$w_{m}^{*}$ & 1.28 & 2.92 & 4.56 & 6.23 \\
$w_{n}^{*}$ & 7.74 & 10.57 & 13.51 & 16.42 \\
\hline
\end{tabular}

Lagrange multiplier on link $e$, on the other hand, is positive in Examples 1 through 3, but is equal to zero in Example 4 since in Example 4 the wage on link $e$ is not at the upper bound of 25. The firms may wish to invest in the links with positive Lagrange multipliers, since doing so, with the large values of the Lagrange multipliers, they can enhance their profits significantly.

We now proceed to conduct additional sensitivity analysis and, in Fig. 3, we report on the profits of the two firms as the link wage bounds are raised, while also graphing these results for Examples 1 through 4. Now, we see something interesting happening, and this further emphasizes the importance of having a rigorous theoretical and computational framework for conducting such exercises. At a wage bound of 30, Firm 1 now has a lower profit than it had at a wage bound of 25, whereas the profit of Firm 2 continues to increase, but at a decreasing rate. Plus, Firm 2 now has a profit exceeding that of Firm 1. And, for link wage bounds of 65 or higher, the profit of Firm 1 stabilizes at 27,225.99 and that of Firm 2 at $39,800.45$. It is important to emphasize that the model has, in effect, link production functions that relate labor, which is fixed, and the wage-responsiveness productivity factor and wage to the product output on each link. However, the product flows are associated with paths, since the product requires multiple supply chain links, beginning from production to ultimate distribution, and the latter, for each firm and demand market pair sum up to the demand. All these are intricately related. Of course, the solution of the supply chain network model without bounds for this dataset would yield the same profits (and equilibrium pattern) as obtained for wages on the supply chain links of 65 or above.

\section{Series 2: Examples 5 Through 8}

In this series of examples we conducted a sensitivity analysis on the $\alpha_{a}$ parameters. Specifically, the data in these examples is as in Example 4 (with the wage bounds all equal to 25), but Example 5 has all the $\alpha_{a}$ s increased fourfold; Example 6 has all the $\alpha_{a}$ s doubled. Example 7, in turn, has the $\alpha_{a}$ s in Example 4 halved, whereas Example 8 has the $\alpha_{a}$ s in Example 4 multiplied by a quarter $\frac{1}{4}$.

\section{Results for Example 5}

The demand market prices for Example 5 are:

$$
\rho_{11}=551.09, \quad \rho_{12}=574.63, \quad \rho_{21}=555.96, \quad \rho_{22}=650.81 .
$$

The profit for Firm 1 is now: 27,741.21 and the profit for Firm 2 is: 40,774.57.

The demand market prices are lower for consumers at the demand markets as compared to their respective values in Example 4. Firm 1 has a lower profit, whereas Firm 2 has a greater profit in Example 5 than it did in Example 4.

\section{Results for Example 6}

The demand market prices for Example 6 are, in turn:

$$
\rho_{11}=557.52, \quad \rho_{12}=580.64, \quad \rho_{21}=567.58, \quad \rho_{22}=657.62 .
$$

The profit for Firm 1 is now: 28,096.79 and the profit for Firm 2 is: 39,826.35. 


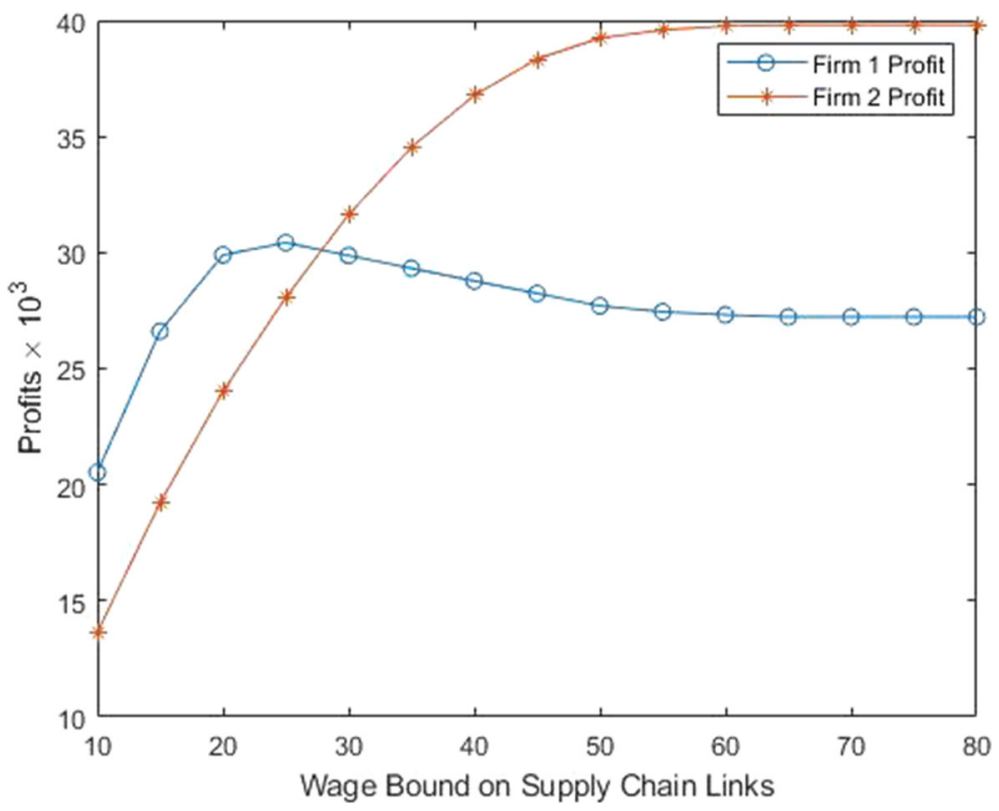

Fig. 3 Sensitivity Analysis for Different Wage Bounds on the Supply Chain Networks of Both Firms and Effects on the Firms' Profits

In Example 6, the demand market prices are lower than in Examples 4 and 5. The profit for Firm 1 is greater than it earned in Example 5, whereas the profit of Firm 2 is lower than it earned in Example 4.

\section{Results for Example 7}

The demand market prices for Example 7 are, in turn:

$$
\rho_{11}=698.99, \quad \rho_{12}=720.35, \quad \rho_{21}=668.37, \quad \rho_{22}=717.36 .
$$

The profit for Firm 1 is now: 23,494.23 and the profit for Firm 2 is: 16,217.42.

Now, with $\alpha_{a}$ s lower than in Example 4, the prices are higher in Example 7 than in Example 4, and also higher (with smaller $\alpha_{a}$ s) than in Example 6. Both firms now suffer a drop in their profits as compared to their profits in Example 6.

\section{Results for Example 8}

The demand market prices for Example 8 are:

$$
\rho_{11}=757.08, \quad \rho_{12}=779.71, \quad \rho_{21}=691.25, \quad \rho_{22}=731.21 .
$$

The profit for Firm 1 is now: 13,512.69 and the profit for Firm 2 is: 8,471.89.

With even smaller values of $\alpha_{a} \mathrm{~s}$, for all links $a \in L$, the prices increase further at the demand markets, and the profits of both firms decrease substantially, as compared to their values in Example 8.

The general progression of demand market prices and firm profits as the $\alpha_{a}$ s decrease makes sense, since, one can see from (4), that, for a fixed amount of labor and wage, a lower $\alpha_{a}$ on a link $a$ would result in a lower product output volume on the link.

\section{Series 3: Examples 9 and 10}

In this series of numerical examples, we are interested in seeing the impacts of one firm having higher wage bounds on its supply chain network activities than the other firm. 


\section{Example 9 Results}

Example 9 has the same data as Example 1, except that $\bar{w}_{a}=10$, for all links $a \in L^{1}$, whereas $\bar{w}_{a}=15$, for all links $a \in L^{2}$.

The modified projection method converges to the following equilibrium path flow pattern:

$$
\begin{aligned}
& x_{p_{1}}^{*}=7.17, \quad x_{p_{2}}^{*}=7.17, \quad x_{p_{3}}^{*}=8.83, \quad x_{p_{4}}^{*}=8.83, \\
& x_{p_{5}}^{*}=2.13, \quad x_{p_{6}}^{*}=4.38, \quad x_{p_{7}}^{*}=11.38, \quad x_{p_{8}}^{*}=13.63 .
\end{aligned}
$$

The demand market prices are:

$$
\rho_{11}=715.33, \quad \rho_{12}=736.66, \quad \rho_{21}=666.16, \quad \rho_{22}=716.16 .
$$

The profit for Firm 1 is: 20,303.18 and the profit for Firm 2 is: 19,364.23.

Note that, as compared to the results in Example 1, Firm 1 now loses in the competition with Firm 2, which is willing to pay its workers higher wages. It has a lower profit than it had in Example 1, whereas Firm 2 enjoys a substantially increased profit, showing, again, that firms can earn greater profits, while paying their workers more. For the computed equilibrium link flows, Lagrange multipliers, and wages for Examples 9 and 10, please, refer to Table 3

\section{Example 10 Results}

Example 10 also has the same data as Example 1, but now we switch and have Firm 1 having the higher wage bounds, in that $\bar{w}_{a}=15$, for all $a \in L^{1}$, with Firm 2 now having wage bounds of $\bar{w}_{a}=10$, for all links $a \in L^{2}$.

The modified projection method converges to the following equilibrium path flow pattern:

$$
\begin{aligned}
& x_{p_{1}}^{*}=11.21, \quad x_{p_{2}}^{*}=11.21, \quad x_{p_{3}}^{*}=12.79, \quad x_{p_{4}}^{*}=12.79, \\
& x_{p_{5}}^{*}=0.40, \quad x_{p_{6}}^{*}=1.90, \quad x_{p_{7}}^{*}=8.60, \quad x_{p_{8}}^{*}=10.10 .
\end{aligned}
$$

The demand market prices are:

$$
\rho_{11}=683.24, \quad \rho_{12}=703.44, \quad \rho_{21}=670.64, \quad \rho_{22}=718.52 .
$$

The profit for Firm 1 is: 26,948.15 and the profit for Firm 2 is: 13,535.19.

We now compare the profits of the two firms to the results in Example 2, where all the wage bounds were set to 15 .

In Example 10, Firm 1, by being willing to pay workers more than Firm 2, earns a higher profit than it did in Example 2, whereas Firm 2 has a substantial decrease in profits, as compared to what it earned in Example 2, where it was willing to pay workers a maximum of 15 (rather than 10 as in Example 10).

Although the above supply chain network examples are stylized, they, nevertheless, provide useful insights for firms, workers, consumers, as well as policy-makers. Of special significance and relevance, is that firms can garner enhanced profits in paying their workers. Of course, the framework assumes wage-responsive productivity factors, but, as noted in the Introduction, economists, including the Nobel laureate Joseph Stiglitz [42], have argued that many workers will be more productive under higher wages. However, it is imperative to conduct sensitivity analysis to see the quantifiable impacts on profits of wage bound increases since, after a point, there may be diminishing returns.

We now proceed to conduct additional sensitivity analysis. In particular, we investigate the impacts of increasing the wage bounds, using Example 9 as the baseline where the wage bound of Firm 1 is lower than than of Firm 2 and we proceed with the following increments of wage bounds for Firm 1 and Firm 2 in parentheses: $(10,15),(15,20), \ldots(70,75)$, on the profits of the firms. The results are reported in Fig. 4. 
Table 3 Equilibrium Link Flows, Lagrange Multipliers, and Hourly Wages for Examples 9 and 10

\begin{tabular}{|c|c|c|}
\hline \multirow[t]{2}{*}{ Notation } & \multicolumn{2}{|c|}{ Equilibrium value } \\
\hline & Example 9 & Example 10 \\
\hline$f_{a}^{*}$ & 16.00 & 24.00 \\
\hline$f_{b}^{*}$ & 16.00 & 24.00 \\
\hline$f_{c}^{*}$ & 16.00 & 24.00 \\
\hline$f_{d}^{*}$ & 16.00 & 24.00 \\
\hline$f_{e}^{*}$ & 32.00 & 48.00 \\
\hline$f_{f}^{*}$ & 14.33 & 22.43 \\
\hline$f_{g}^{*}$ & 17.67 & 25.57 \\
\hline$f_{h}^{*}$ & 13.50 & 9.00 \\
\hline$f_{i}^{*}$ & 18.00 & 12.00 \\
\hline$f_{j}^{*}$ & 13.50 & 9.00 \\
\hline$f_{k}^{*}$ & 18.00 & 12.00 \\
\hline$f_{l}^{*}$ & 31.50 & 21.01 \\
\hline$f_{m}^{*}$ & 6.50 & 2.31 \\
\hline$f_{n}^{*}$ & 25.00 & 18.70 \\
\hline$\lambda_{a}^{*}$ & 0.00 & 0.00 \\
\hline$\lambda_{b}^{*}$ & 0.00 & 0.00 \\
\hline$\lambda_{c}^{*}$ & 0.00 & 0.00 \\
\hline$\lambda_{d}^{*}$ & 0.00 & 0.00 \\
\hline$\lambda_{e}^{*}$ & 473.48 & 320.83 \\
\hline$\lambda_{f}^{*}$ & 0.00 & 0.00 \\
\hline$\lambda_{g}^{*}$ & 0.00 & 0.00 \\
\hline$\lambda_{h}^{*}$ & 526.13 & 580.40 \\
\hline$\lambda_{i}^{*}$ & 505.48 & 567.23 \\
\hline$\lambda_{j}^{*}$ & 0.00 & 0.00 \\
\hline$\lambda_{k}^{*}$ & 0.00 & 0.00 \\
\hline$\lambda_{l}^{*}$ & 0.00 & 0.00 \\
\hline$\lambda_{m}^{*}$ & 0.00 & 0.00 \\
\hline$\lambda_{n}^{*}$ & 0.00 & 0.00 \\
\hline$w_{a}^{*}$ & 3.20 & 4.80 \\
\hline$w_{b}^{*}$ & 3.20 & 4.80 \\
\hline$w_{c}^{*}$ & 5.93 & 8.89 \\
\hline$w_{d}^{*}$ & 7.62 & 11.43 \\
\hline$w_{e}^{*}$ & 10.00 & 15.00 \\
\hline$w_{f}^{*}$ & 4.78 & 7.48 \\
\hline$w_{g}^{*}$ & 7.36 & 10.66 \\
\hline$w_{h}^{*}$ & 15.00 & 10.00 \\
\hline$w_{i}^{*}$ & 15.00 & 10.00 \\
\hline$w_{j}^{*}$ & 5.00 & 3.33 \\
\hline$w_{k}^{*}$ & 6.67 & 4.45 \\
\hline$w_{l}^{*}$ & 7.00 & 4.67 \\
\hline
\end{tabular}


Table 3 continued

\begin{tabular}{lll}
\hline Notation & \multicolumn{2}{l}{ Equilibrium value } \\
\cline { 2 - 3 } & Example 9 & Example 10 \\
\hline$w_{m}^{*}$ & 3.10 & 1.10 \\
$w_{n}^{*}$ & 10.42 & 7.79 \\
\hline
\end{tabular}

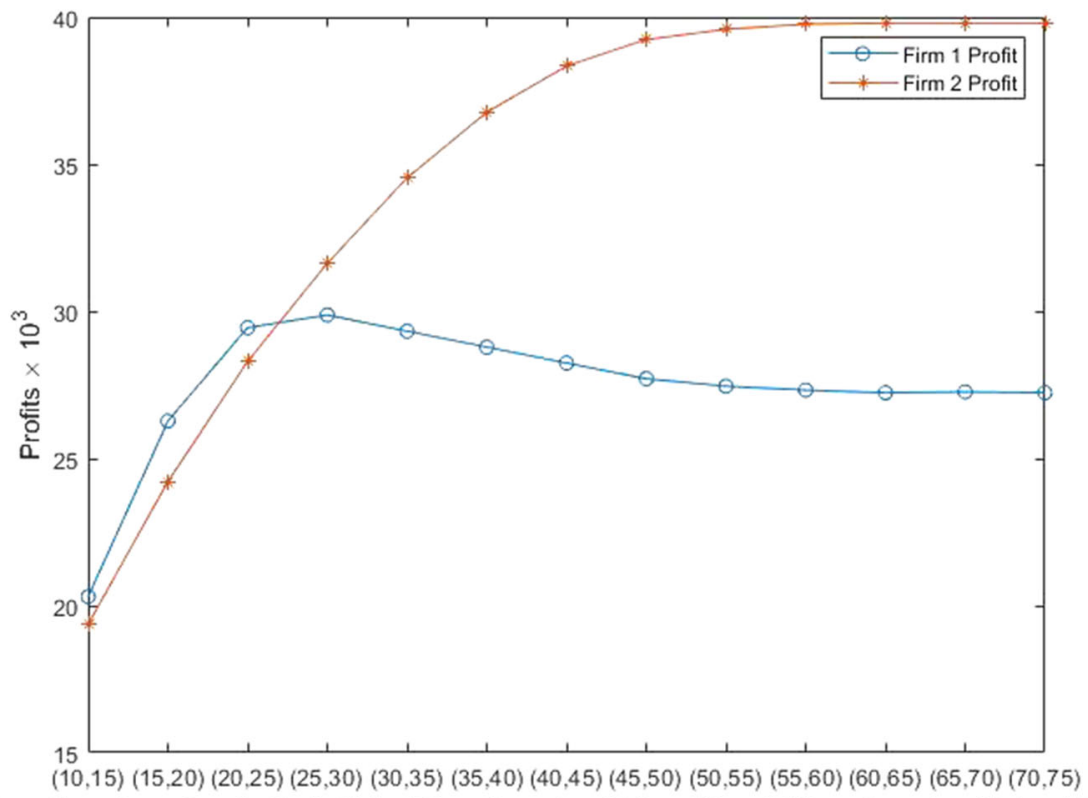

Wage Bounds on Supply Chain Links (Wage Bound on Links of Firm 1, Wage Bound on Links of Firm 2)

Fig. 4 Sensitivity Analysis for Different Wage Bounds on the Supply Chain Networks of Both Firms, with Firm 1 Having a Lower Bound than Firm 2, and Effects on the Firms' Profits

Firm 1 has profits higher than Firm 2 until the wage bounds of $(25,30)$, after which the profit of Firm 1 decreases, but that of Firm 2 increases, but, at a decreasing rate, until it stabilizes at 38.800.45 and the profit of Firm 1 stabilizes at: 27,255.99.

We continue the sensitivity analysis, but now Firm 1 has a higher wage bound than Firm 2 and we proceed with computing the solution to Example 9 but now with wage bounds of: $(15,10),(20,15),(25,20), \ldots,(75,70)$. We report the profits of the two firms in Fig. 5.

Firm 1 now enjoys a higher profit at $(15,10)$ than it did at $(10,15)$ in Fig. 4 ; the same for $(20,15)$ than at $(15,20)$ in Fig. 4 and so on, suggesting, again, that lifting wage bounds can have positive effects on a firm's profits. Firm 2, on the other hand, now has consistently lower profit at $(15,10)$ than it did at $(10,15)$ in Fig. 4; the same for $(20,15)$ than at $(15,20)$, and so on. At $(70,65)$, as also seen in previous results, the profits reach 27,225.99 for Firm 1 and 39,800.45 for Firm 2, and remain there for $(75,70)$ (and so on). Firm 1, while enjoying increasing profits at the first three points, then encounters a reduction in profit at $(30,25)$ and that trend continues until its profit of 27,225.99. Firm 2 enjoys an increase in profits as we move along the $\mathrm{x}$ axis in Fig. 5, with stabilization at the profit level of 39,800.45. 


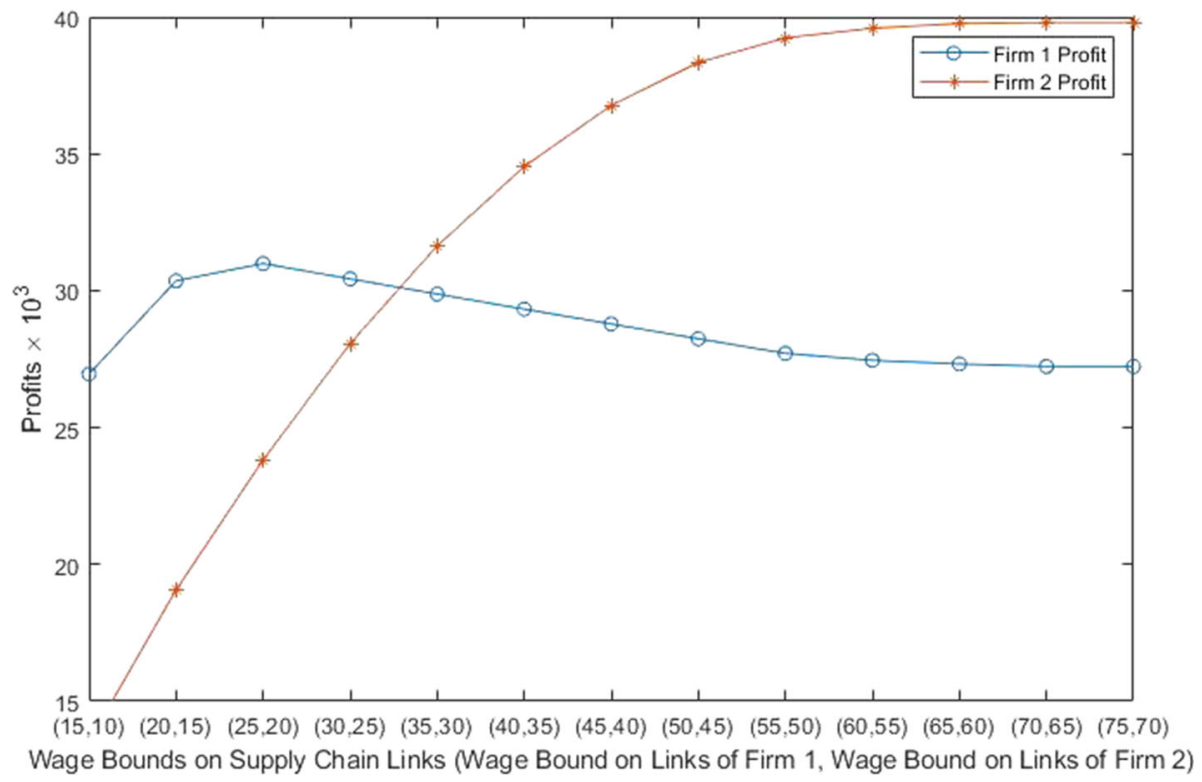

Fig. 5 Sensitivity Analysis for Different Wage Bounds on the Supply Chain Networks of Both Firms, with Firm 1 Having a Higher Bound than Firm 2, and Effects on the Firms' Profits

\section{Summary and conclusions}

The COVID-19 pandemic has demonstrated the importance of labor and its productivity to supply chains of numerous different products. Disruptions to labor have negatively impacted production, the transportation of goods, and even storage, as workers got ill, and many perished.

In this paper, we introduce a novel game theory model that integrates labor into supply chains and that captures wage-responsive productivity associated with the various supply chain network activities. We present first a model without wage bounds on links, representing the maximum hourly wages that firms are willing to pay, and then extend the model to include such wage bounds. The link productivity factors are linearly increasing in wages.

The governing equilibrium concept in the competitive game theory models is that of Nash equilibrium. We utilize the theory of variational inequalities to formulate the equilibrium conditions and, for the model with wage bounds, we conduct a Lagrange analysis, which also yields an alternative variational inequality formulation with nice features for computations.

Our numerical results reveal that firms that are willing to pay their workers higher hourly wages can enjoy higher profits, and can, hence, beat their competitors, in terms of lower prices for consumers at the demand markets, higher wages for the workers, and, of course, higher profits. Our framework also has relevance for addressing, in part, the labor shortage in various industrial sectors and even in freight services since we show that, even with fixed labor amounts associated with various supply chain network economic activities, having more productive labor, that is wage-sensitive, can yield financial gains for firms. However, it is important to conduct sensitivity analysis, since, after a point that the wage bounds are raised, a firm may experience a decline in profits. Furthermore, ultimately, the profits of competing 
firms may stabilize and there will be no change with increases in the wage bounds. This is also interesting, since it suggests a natural type of wage "cap."

This work adds to the literature on the integration of principles from economics and operations research perspectives for supply chains.

Future research directions can include extending some of the concepts formulated herein to various service sectors, including the healthcare sector, which has also faced many disruptions in the COVID-19 pandemic, along with decreases in productivity, as well as shortfalls and shortages in labor. Another possibility for future research is constructing a multiperiod supply chain network model with labor and productivity factors. Furthermore, it would be interesting to investigate the case of labor that is elastic, rather than fixed, and that, possibly, could be allocated across tasks, with associated costs of training, etc.

Acknowledgements The author thanks the two anonymous reviewers and the Editor for their very helpful comments and suggestions on an earlier version of this paper. This paper is dedicated to all essential workers, whose work and sacrifices in the pandemic are being acknowledged with great appreciation. Special thanks to Stephen Cumberbatch, technical worker, who kept the computer system that I use at UMass Amherst up and running, even coming in, when needed, in snow storms.

\section{References}

1. Arrow, K.J., Debreu, G.: Existence of an equilibrium for a competitive economy. Econometrica 22, 265-290 (1954)

2. Barbagallo, A., Daniele, P., Maugeri, A.: Variational formulation for a general dynamic financial equilibrium problem: balance law and liability formula. Nonlinear Anal. Theory Methods Appl. 75(3), 1104-1123 (2012)

3. Burki, T.: Global shortage of personal protective equipment. Lancet Infectious Diseases 20(7), 785-786 (2020)

4. Cardona, C.: Nationwide shortage of truck drivers impacting Central Florida. Orlando.com. (2021). Available at: https://www.clickorlando.com/news/local/2021/04/01/nationwide-concern-over-shortageof-truck-drivers/

5. Caruso, V., Daniele, P.: A network model for minimizing the total organ transplant costs. Eur. J. Oper. Res. 266(2), 652-662 (2018)

6. Colajanni, G., Daniele, P., Giuffrè, S., Nagurney, A.: Cybersecurity investments with nonlinear budget constraints and conservation laws: variational equilibrium, marginal expected utilities, and Lagrange multipliers. Int. Trans. Oper. Res. 25, 1443-1464 (2018)

7. Conerly, B.: The labor shortage is why supply chains are disrupted. Forbes, July 7 (2021)

8. Corkery, M., Yaffe-Bellany, D.: The food chains weakest link: Slaughterhouses. The New York Times. April 18 (2020)

9. Daniele, P.: Variational inequalities for static equilibrium market, Lagrangian function and duality. In: Giannessi, F., Maugeri, A., Pardalos, P.M. (eds.) Equilibrium Problems: Nonsmooth Optimization and Variational Inequality Models, pp. 43-58. Kluwer Academic Publishers, Amsterdam (2001)

10. Daniele, P.: Time-dependent spatial price equilibrium problem: existence and stability results for the quantity formulation model. J. Global Optim. 28(3-4), 283-295 (2004)

11. Daniele, P.: Dynamic Networks and Evolutionary Variational Inequalities. Edward Elgar Publishing, Cheltenham, United Kingdom (2006)

12. Daniele, P., Sciacca, D.: A dynamic supply chain network for PPE during the Covid-19 pandemic. J. Appl. Numeric. Opt. 3(2), 403-424 (2021)

13. db group: Port congestion - drivers and impacts on international freight forwarding. May 31. (2021). Available at:https://www.dbgroup.net/en/news/port-congestion-drivers-and-impacts-internationalfreight-forwarding

14. Debreu, G.: A social equilibrium existence theorem. Proc. Natl. Acad. Sci. U.S.A. 38, 886-893 (1952)

15. Fisman, R., Luca, M.: How Amazon's higher wages could increase productivity. Harvard Business Review. October 10. (2018). Available at: https://hbr.org/2018/10/how-amazons-higher-wages-could-increaseproductivity 
16. Flannery, R.: Factories facing severe labor shortages in China, p. 16. U.S. business group says, Forbes, February (2020)

17. Gabay, D., Moulin, H.: On the uniqueness and stability of Nash equilibria in noncooperative games. In: Bensoussan, A., Kleindorfer, P., Tapiero, C.S. (eds.) Applied Stochastic Control of Econometrics and Management Science, pp. 271-294. North-Holland, Amsterdam, The Netherlands (1980)

18. Karp, E.: The case for raising wages in manufacturing. Forbes, Match 2. (2021). Available at: https://www.forbes.com/sites/ethankarp/2021/03/02/the-case-for-raising-wages-in-manufacturing/? $\mathrm{sh}=565 \mathrm{~d} 8 \mathrm{a} 755480$

19. Kinderlehrer, D., Stampacchia, G.: An Introduction to Variational Inequalities and Their Applications. Academic Press, New York (1980)

20. Korpelevich, G.M.: The extragradient method for finding saddle points and other problems. Matekon 13, 35-49 (1977)

21. Levine, D.I.: Can wage increases pay for themselves? Test with a production function. Econom. J. 102, 1102-115 (1992)

22. Lolla, N., O'Rourke, D.: Factory benefits to paying workers more: The critical role of compensation systems in apparel manufacturing. PLOS ONE, February 20, (2020). https://doi.org/10.1371/journal. pone. 0227510

23. Luckstead, J., Nayga, R.M., Jr., Snell, H.A.: Labor issues in the food supply chain amid the COVID-19 pandemic. Appl. Econ. Perspect. Policy 43(1), 382-400 (2021)

24. Nagurney, A.: Network Economics: A Variational Inequality Approach, second and, revised Kluwer Academic Publishers, Dordrecht, The Netherlands (1999)

25. Nagurney, A.: Perishable food supply chain networks with labor in the Covid-19 pandemic. In press in: Dynamics of Disasters - Impact, Risk, Resilience, and Solutions, I.S. Kotsireas, A. Nagurney, P.M. Pardalos, and Arsenios Tsokas, Editors, Springer Nature Switzerland AG, pp. 173-193 (2021)

26. Nagurney, A.: Supply chain game theory network modeling under labor constraints: applications to the Covid-19 pandemic. Eur. J. Oper. Res. 293(3), 880-891 (2021)

27. Nagurney, A.: Wage-dependent labor and supply chain networks. Accepted for publication in: Analysis, Geometry, Nonlinear Optimization and Applications, P.M. Pardalos and T.M. Rassias, Editors, World Scientific Publishing, Singapore (2021)

28. Nagurney, A., Besik, D., Yu, M.: Supply chain network capacity competition with outsourcing: a variational equilibrium framework. J. Global Optim. 69(1), 231-254 (2017)

29. Nagurney, A., Daniele, P.: International human migration networks under regulations. Eur. J. Oper. Res. 291(3), 894-905 (2021)

30. Nagurney, A., Daniele, P., Nagurney, L.S.: Refugee migration networks and regulations: a multiclass, multipath variational inequality framework. J. Global Optim. 78, 627-649 (2020)

31. Nagurney, A., Dutta, P.: A multiclass, multiproduct Covid-19 convalescent plasma donor equilibrium model. Operations Research Forum 2, 31 (2021)

32. Nagurney, A., Yu, M., Besik, D.: Supply chain network capacity competition with outsourcing: a variational equilibrium framework. J. Global Optim. 69(1), 231-254 (2017)

33. Nash, J.F.: Equilibrium points in n-person games. Proc. National Academy Sci. USA 36, $48-49$ (1950)

34. Nash, J.F.: Noncooperative games. Ann. Math. 54, 286-298 (1951)

35. Nickel, R., Walljasper, C.: Canada, p. 6. U.S. farms face crop losses due to foreign worker delays, Reuters, April (2020)

36. Palmer, A.: Amazon to hike wages for over 500,000 workers. CNBC.com, April 28. (2021). Available at: https://www.cnbc.com/2021/04/28/amazon-to-hike-wages-for-over-500000-workers-to-up-to3-an-hour.html

37. Polansek, T., Huffstutter, P.J.: Piglets aborted, chickens gassed as pandemic slams meat sector. Reuters, April 27. (2020). Available at: https://www.reuters.com/article/us-health-coronavirus-livestock-insight/ piglets-aborted-chickensgassed-as-pandemic-slams-meat-sector-idUSKCN2292YS

38. Reuter, D., Winck, B.: Under Armour is the latest company to raise wages during the pandemic. Here are the major firms that hiked pay over the past year. Business Insider May 19. (2021). Available at:https://www.businessinsider.com/companies-raising-wages-workers-pandemic-hiring-chipotlecostco-target-walmart-2021-5

39. Saberi, S., Cruz, J.M., Sarkis, J., Nagurney, A.: A competitive multiperiod supply chain network model with freight carriers and green technology investment option. Eur. J. Oper. Res. 266(3), 934-949 (2018)

40. Salarpour, M., Nagurney, A.: A multicountry, multicommodity stochastic game theory network model of competition for medical supplies inspired by the Covid-19 pandemic. Int. J. Prod. Econ. 235, 108074 $108074(2021)$

41. Schrotenboer, B.: US agriculture: Can it handle coronavirus, labor shortages and panic buying? USA Today. April 4 (2020) 
42. Stiglitz, J.E.: Alternative theories of wage determination and unemployment: The efficiency wage model. In: The Theory and Experience of Economic Development - Essays in Honor of Sir W. Arthur Lewis. M. Gersovitz, C.F. Diaz-Alejandro, G. Ranis, and M. R. Rosenzweig, Editors, George Allen \& Unwin, London, England, pp. 78-106 (1982)

43. Strain, M.A.: The link between wages and productivity is strong. The Economic Strategy Group. The Aspen Institute. February 4. (2019). Available at: https://www.aspeninstitute.org/longform/expandingeconomic-opportunity-for-more-americans/the-link-between-wages-and-productivity-is-strong/

44. Toyasaki, F., Daniele, P., Wakolbinger, T.: A variational inequality formulation of equilibrium models for end-of-life products with nonlinear constraints. Eur. J. Oper. Res. 236(1), 340-350 (2014)

45. Van Biesebroeck, J.: How tight is the link between wages and productivity? A survey of the literature, International Labour Office, Geneva, Switzerland (2015)

46. Wolters, J., Zilinsky, J.: Higher wages for low-income workers lead to higher productivity. Peterson Institute for International Economics. January 13. (2015). Available at: https://www.piie.com/blogs/realtimeeconomic-issues-watch/higher-wages-low-income-workers-lead-higher-productivity

47. World Bank: Poverty. In: World Development Report 2015: Mind, Society, and Behavior. Washington, DC (2015)

48. Yellen, J.L.: Efficiency wage models of unemployment. Am. Econom. Rev. 74(2), 200-205 (1984)

49. Yu, M., Cruz, J.M., Li, D.M., Masoumi, A.H.: A multiperiod competitive supply chain framework with environmental policies and investments in sustainable operations. In: press in the European Journal of Operational Research (2021)

Publisher's Note Springer Nature remains neutral with regard to jurisdictional claims in published maps and institutional affiliations. 